\title{
Research on Emergency Strategies of College Students' Mass Incidents
}

\author{
Jiaming Ma, Lei Qin,Sijie Zhang \\ College of Resources and Environment Engineering \\ Wuhan University of Technology \\ Wuhan, P.R.China, 430070 \\ Email:605520413@qq.con,1836811519@qq.com,1019775713@qq.com
}

\begin{abstract}
The purpose of this research is to deeply study the current situation and characteristics of college students' group emergencies, analyze the causes of the emergencies and find out the corresponding emergency management strategies, so as to provide reference for the early warning and response of mass incidents in colleges and universities. This study combines the basic theories of management, sociology, and psychology,and mainly discusses the principles of emergency management of mass incidents in colleges and universities based on early warning mechanism and draws the following conclusions: The countermeasures of mass incidents in colleges and universities should focus on three aspects: humanization strategy, coordination strategy and public opinion response.
\end{abstract}

Keywords-universities, mass incidents, emergency management, strategy

\section{INTRODUCTION}

In recent years, under this social and economic background, the frequent occurrence of mass incidents in colleges and universities across China has brought a lot of adverse effects to colleges and society. Emergency management of mass incidents has been incorporated into the management objectives of many universities. In-depth study of emergency strategies for group emergencies is the need of implementing the "people-centered" development concept in colleges and universities,and it is of great significance to guarantee the normal order of campus, maintain social harmony and stability, and safeguard the safety of people's life and property.

\section{DOMESTIC AND FOREIGN RESEARCH STATUS}

In some countries, the study on the concept and connotation of mass emergencies on campus is regarded as a specific subset of common mass emergencies, which is known as "a comprehensive response plan of campus crises". At present, there are a lot of researches in this field at home and abroad, however, the definition of many concepts is controversial. Ou Yongmei believes that mass incident of college students refers to all kinds of sudden, unexpected and urgent mass incident of college students, which is affected by international situation, domestic situation, college management and other factors and concerns the vital interests of college students, and causes serious consequences or significant influences[1] (Ou Yongmei, Li Jinshun, 2007) . At the beginning of the formal emergence of the concept of "mass incident in colleges and universities", domestic and foreign scholars tend to explore its causes[2] (Ma
Jing, 2015) . Liu lidong concluded that the lack of social cognition of some students was the main factor that led to the group incident, while the weak legal concept of a few students was the subjective factor that led to the group incident[3] (Liu Lidong, 2011).

In foreign countries, the majority of group emergencies in colleges and universities are case-specific and provide universal results, the results of emergency management often appear in the form of specific emergency procedures and operational guidelines,like the "acute psychological trauma" management guidelines of American campuses[4] (Dai Weihui, Wan Xiqiong, Liu Xiaoyi, 2011). In China, the research on the emergency management of mass incidents in colleges and universities is manifested as the research on the specific strategies of causes and responses. Li yao-yuan divided emergency management into four stages: mitigation, preparation, response and recovery[5] (Li Yaoyuan, 2013).

As for the emergency management of mass incidents in colleges and universities, most of the people directly apply the theories and methods of emergency management to campus practice, and lack the theories, methods and strategy system of group emergency management based on the characteristics of colleges and universities. However, there are relatively mature theories, methods and systematic researches on the early-warning management of mass incidents in colleges and universities, among which the most important ones are: (1) lack of researches based on questionnaires and descriptive statistics; (2) lack of research on the technical platform and alarm criteria of the early-warning system for mass emergencies in colleges and universities; (3) the simulation method is rarely used in the study of mass emergencies in universities; (4) there is not enough research on the coping mode of mass emergencies in colleges and universities. These are the key points to be discussed in this study.

\section{DEFINITION AND CHARACTERISTICS OF MASS INCIDENTS IN COLLEGES AND UNIVERSITIES}

From the perspective of set theory, group emergencies in colleges and universities are the collection of colleges, emergencies and participating groups, however, the three are not simply superimposed, but a complex dynamic combination (Fig. 1). 


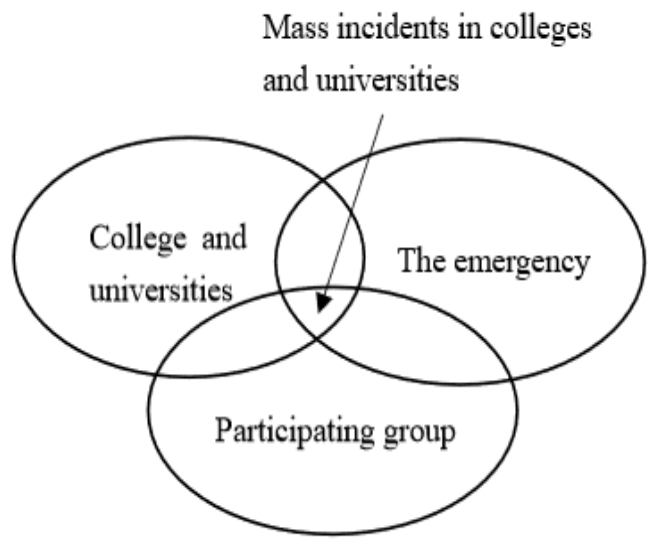

Fig. 1. Concept map of mass incidents in colleges and universities

The concept of mass incident in colleges and universities can be divided into broad sense and narrow sense. In a narrow sense, mass incidents in colleges and universities refers specifically to mass incidents of college students, that is, colleges and universities are affected by specific major events at home and abroad, changes in college system and management, natural disasters inside and outside campus or man-made and social factors, or it may be a group behavior event involving the immediate interests of college students, resulting in a variety of sudden occurrence, which makes people unprepared and brings harm to the school and adverse social impact.

The mass incident in colleges and universities not only has the common characteristics of the general group, but also its particularity. The characteristics of physical emergencies in colleges and universities are mainly reflected in the following two aspects:

\section{A. Suddenness}

One of the essential characteristics of mass emergencies in colleges and universities is its typical suddenness. College mass emergencies are usually caused by the direct stimulation of some external accidental events. Some college emergencies have gestation period, some are just a coincidence, and then release and spread through certain trigger factors; University emergencies have the butterfly effect, which is the continuous amplification of the influence in the progressive process. Meanwhile, the occurrence time, occurrence mode, evolution direction, development scale, duration and damage degree of mass emergencies in universities are all uncertain and unpredictable[6] (Tang Pingqiu, Zhou Qiang, 2015) .

\section{B. Harmfulness}

Mass incidents in colleges and universities tend to go negative, bringing adverse effects on faculty, staff, schools and society, ultimately affecting the normal work and study of students and teachers, and causing extreme mental and psychological panic among teachers and students[7] (Wang Jing, He Yunfeng, Feng Xipeng, 2015) . The occurrence of mass emergencies in colleges and universities not only causes the turbulence of our school, but also produces imitation effect and causes students from other colleges to respond or have similar incidents, it is also easy to be used by off-campus personnel, which leads to the expansion of the situation, chaos and loss of control, and makes it extremely difficult for the school and the government to deal with mass emergencies in colleges and universities, becoming an unstable factor that goes against social harmony and stability[8] (Wlezien C, 2004) .

\section{Diffusivity}

Colleges and universities are crowded places where students eat and live,teachers work together to conduct teaching and research activities. In addition, colleges and universities are closely connected with the government and face a large number of parents, alumni and cooperative units, which makes colleges and universities increasingly open and interact with the outside world in a multi-level and all-round way. As a result, mass incidents in colleges and universities can easily become the hot spots of social attention and be promoted by external forces. At the same time, in the Internet age, information dissemination is very fast. Once there are group emergencies, its information will spread rapidly, and the crowd will be quickly convened, resulting in the rapid expansion of the number of participants in the emergency, various media information and even rumors.

\section{Complexity}

Group emergencies in colleges and universities are often hidden . The concealment of organizational behavior is mainly reflected in the form of activities of universities and online public opinion. Under normal circumstances, college groups organize a variety of group activities, and there are many activities at different locations at the same time. The abundant life of students in and off class makes it difficult to find the signs of mass incidents from various activities. It is difficult to solve group emergencies in college. Mass incidents in colleges and universities are mostly internal traditions formed by internal contradictions. The appeals of teachers and students are sometimes justified but partly illegal, or the appeals are legal and the actions are illegal, which increases the difficulty of solving contradictions.

\section{PRINCIPLES OF EMERGENCY MANAGEMENT FOR MASS INCIDENTS IN COLLEGES AND UNIVERSITIES}

In the management of mass incidents in colleges and universities, we should firmly grasp three aspects of people, law and emotion, attach importance to the three dimensions of rapidity, anticipation and efficiency, adhere to the principle of humanism, law and agility, and respond quickly, put the word of prevention in the first and pay attention to actual effect[9] (Li Fuchang, 2012).

\section{A. Principle of humanism}

The main body of mass emergencies in colleges and universities is the students, who are the pillars and talents of the country. We should treat each person in the emergencies well, deal with emergencies humanely and flexibly, and always put the safety of students in the first place. The second is to minimize all kinds of negative effects and losses. When it comes to handling and decision-making of mass emergencies in colleges and universities, we should take whether the majority of students approve of and benefit from it as the starting point, and fully safeguard and respect the rights and 
interests of students; In dealing with emergencies, we should make close contact with students to better understand the causes of emergencies, and observe the suffering of victims and take students' reasonable needs and rights and interests as the key factors.

\section{B. Principles of law}

The management of mass emergencies in universities must follow the relevant laws and regulations of the state and formulate the corresponding management system of mass emergencies in colleges and universities according to the existing laws and regulations. At the same time, through a variety of ways to conduct propaganda and education of students in school so that students can understand and abide by the school management rules, violations by students should be dealt with seriously, strictly implement the management system and establish the prestige of the school system. When colleges and universities are faced with mass emergencies, in the process of identifying, warning, controlling and dealing with it, they need to deal with the incidents according to legal procedures and standardized steps, clarify the responsibilities of all departments and personnel, and make sure there are rules to follow. On the basis of legal system, it is very important to make rules and regulations scientifically and adopt scientific management methods.

\section{Principles of agility}

In order to reduce losses and negative effects, managers of mass emergencies in colleges and universities should rush to the scene at the first time, quickly understand the conflicts, and take the most effective measures to control the situation in the shortest time. At the same time, relevant organizations and individuals should establish the concept of the overall situation and the sense of responsibility and must follow established procedures and be in place quickly, actively assist and cooperate with other departments to carry out various work while giving full play to its emergency management functions, so as to quickly control mass emergencies to a certain extent, reduce their negative effects and minimize losses.

\section{Principles of Advance}

The so-called pre-principle means that in the emergency management of mass incidents in colleges and universities, it is necessary to highlight pre-words, pay attention to prevention, early warning, attach importance to plans, advance preparation, and pay attention to pre-control. In particular, the establishment of early warning mechanism, the construction and operation of early warning system, the coordination of early warning process, and the rational and effective use of early warning information are the main contents. The work of early warning, prevention and control should be done before anything happens, and the hidden danger of mass incidents should be eliminated as far as possible.

\section{EMERGENCY STRATEGIES FOR MASS INCIDENTS IN COLLEGES AND UNIVERSITIES}

\section{A. Humanized strategies for emergency management of mass incidents in colleges and universities}

The humanized strategy of mass incidents in colleges and universities means that the prevention and solution of mass incidents in colleges and universities should fully reflect the people-oriented view and proceed from the interests of students, and in every stage of mass incidents in colleges and universities, students' demands should be fully considered in advance prevention, event control and post-treatment, and students' interests should be the basis of everything.Therefore, the humanized strategy of university mass incident is the embodiment of the principle of humanism. Take the interests of students as the starting point and the center, pay attention to the needs to protect their interests, try to understand the requirements of students in their position, put oneself in the shoes of students, try to meet the reasonable demands of students. In this way, it is easier to find the causes of mass incidents in universities, so as to effectively prevent and better deal with the aftermath. The administrators of colleges and universities can implement the humanized strategy from three aspects of management thought, management system and management mode. Management ideology should reflect that the management of colleges and universities is close to students' reality and life. Colleges and universities should regard students as the main body of management and service, and make every effort to maintain the smooth realization of students' legal rights, so as to realize the management system that the management goals of colleges and universities are consistent with the development and growth goals of students. In terms of management system, relevant management system should be formulated according to the specific economic, cultural, physiological and psychological conditions of college students. The management style should be flexible and easy for students to understand, especially at the part of the interests closely related to students' life.

\section{B. Collaborative strategies for emergency management of mass incidents in colleges and universities}

Cooperative strategy is the necessity of early warning and response of mass incidents in colleges and universities. The development trend of college emergency management requires the establishment of emergency management coordination mechanism. The emergency management of mass incidents in colleges and universities is characterized by information sharing and optimal allocation of resources. The subjects involved in mass emergencies in colleges and universities are diversified. Many functional departments of colleges and universities are involved, it needs to rely on the information management system to track and respond to the latest situation of group emergencies, and at the same time reflect the implementation of functions of each department, so that each department can coordinate, receive and transport the needed materials to the necessary places in time according to the work situation or report of other departments, which can save time and cost. The suddenness of mass emergencies in colleges and universities makes it difficult for people to control the specific time, actual scale and impact of the outbreak and the resulting loss of property and human life is also uncertain. Therefore, it is very important to scientifically respond to mass emergencies in colleges and universities, cooperate with all parties in response to emergencies, and operate as a whole and a system, which can monitor, prevent and deal with mass emergencies in colleges and universities in an all-round and large-scale way. It can effectively integrate resources and improve the efficiency of emergency management by integrating various functional 
departments of colleges and universities into the group emergency management system.

\section{Public opinion response strategies for mass emergency management in colleges and universities}

Public opinion management in the emergency management of mass emergencies in colleges and universities should be the whole-process management, covering three links of emergency management of prevention in advance, event control and handling afterwards. The public opinion response mechanism is shown in Fig. 2.

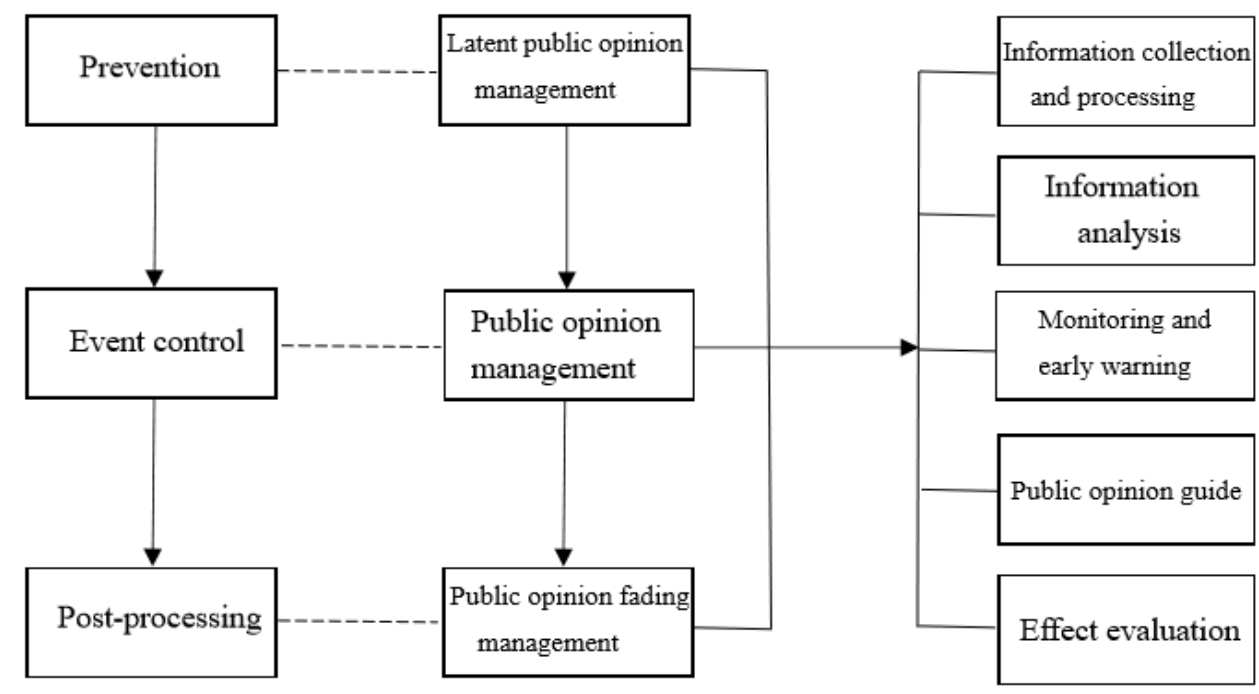

Fig. 2. Public opinion response mechanism for mass emergencies

According to Fig. 2, public opinions on mass emergencies in colleges and universities are in line with the whole process of emergency management. Prevention in advance is the latent stage of public opinion; control of events after the outbreak of events is the outbreak stage of public opinion; and public opinion is fading after mass incidents in colleges and universities subside. The characteristics of public opinion at different stages are different, but the public opinion guidance mechanism is the same. There are five mechanisms to deal with public opinion, including information collection and processing, information analysis, monitoring and warning, public opinion guidance and effect evaluation.

The formulation of public opinion response system is not only the guarantee system of public opinion response strategy, but also the implementation guidelines of public opinion response strategy, which is conducive to the correct implementation of public opinion response. The public opinion response system should set up appropriate requirements for public opinion managers, standardize behaviors, standardize the work and operation process of public opinion response, and standardize information release, which can guarantee the professional quality of public opinion management personnel, pledge the smooth and effective implementation of public opinion work, clarify work responsibilities, and ensure that public opinion response work is kept at a high level.

Collecting public opinion information of colleges and universities extensively and using information technology for real-time monitoring can grasp the development trend of public opinion, track the published source of public opinion at the same time and contain adverse public opinion information from the source to eliminate its influence, it is also necessary to judge the trend of public opinion in colleges and universities according to the public opinion information collected, take necessary measures to monitor the development trend of public opinion and realize effective prevention of emergency management.

Scientific analysis of public opinion information requires information analysts to timely analyze public opinion within a certain period of time. Public opinions have time value, the public opinions at a certain time are the attitudes and opinions of students at a certain stage, continuous time can help information analysts analyze the trend of public opinions, find problems in time and make appropriate responses[10] (Zeng Shengquan, 2012) .

\section{CONCLUSION}

Mass incidents in colleges and universities especially refer to mass incidents of college students, which not only have common characteristics of general groups, but also have their particularity, such as suddenness and harmfulness. In the management of mass incidents in colleges and universities, the three aspects of people, law and emotion should be firmly grasped, the three dimensions of speed, anticipation and efficiency should be emphasized and the principles of humanism, law and agility should be adhered to. Humanistic strategy, collaborative strategy and public opinion response strategy are the three magic weapons to deal with mass emergencies in colleges and universities, which provide the reference for the efficient disposal of mass emergencies. 


\section{REFERENCES}

[1] Ou Yongmei, Li Jinshun. Research on the mechanism of dealing with mass emergencies of college students [J].Journal of Guangdong university of technology (social science edition), 2007 (9): 78-81.(In Chinese)

[2] Ma Jing. Problems and countermeasures of college students' safety education in the new era [J].New campus (first day), 2015(1):200. (In Chinese)

[3] Liu Lidong. Current situation and countermeasures of college students' safety education [J].Forest teaching, 2011(3): 54-55. (In Chinese)

[4] Dai Weihui, Wan Xiqiong, Liu Xiaoyi. Emergency event: Internet spread, psychological impacts and Emergency management [J]. Journal of Computers, 2011, 6(8): 1748-1755.

[5] Li Yaoyuan. Emergency management series: emergency plan management $[\mathrm{M}]$.Beijing: BJ University press, 2013. (In Chinese)
[6] Tang Pingqiu, Zhou Qiang. Coping strategies of college students' crisis events from the perspective of social combustion theory [J].China higher education, 2015 (6): 43-46. (In Chinese)

[7] Wang Jing, He Yunfeng, Feng Xipeng. The connotation, occurrence factors and development process of college students' online public opinions -- interpretation from the perspective of sociology [J].Journal of Xinzhou normal university, 2015 (4) : 58-62. (In Chinese)

[8] Wlezien c. Patterns of representation: Dynamics of public preferences and policy [J]. Journal of Politics, 2004, 66(1): 1-24.

[9] Li Fuchang. Study on emergency early warning system for university students[C].Innovation Management and Industrial Engineering (ICIII 2012), 2012, 1:490-493.

[10] Zeng Shengquan. Guidelines for public opinion response to emergencies: theoretical manual and practical guide for public opinion response to emergencies in China [M].Guangzhou: Nanfang daily publishing house, 2012. (In Chinese) 